\title{
The Link Between Adverse Childhood Experiences and Financial Security in Adulthood
}

\author{
Cynthia L. Harter ${ }^{1} \mathbb{D} \cdot$ John F. R. Harter ${ }^{1} \mathbb{C}$
}

Accepted: 30 August 2021 / Published online: 9 September 2021

(c) The Author(s), under exclusive licence to Springer Science+Business Media, LLC, part of Springer Nature 2021

\begin{abstract}
This study provides an evidence-based link between adverse childhood experiences (ACEs) and adult financial wellbeing. Drawing on a comprehensive financial wellbeing framework that was developed by the Consumer Financial Protection Bureau, we analyze data from the Behavioral Risk Factor Surveillance System, a survey designed primarily to measure health behaviors and outcomes, but which also asks about financial wellbeing aspects such as food and housing security. We use ordered probit analysis to investigate how respondents' self-reported levels of food security and housing security are influenced by demographics that include remembered ACEs and find that, at various income levels, financial stress in adulthood is related to childhood trauma. This interdisciplinary approach to studying financial outcomes extends work in public health and psychology that establishes a link between ACEs and adult physical and mental health measures. The finding is timely as policy makers craft responses to global public health, financial, and other shocks. Recognizing this link between ACEs and adult financial wellbeing provides additional evidence that educators, therapists, social workers, and other professionals should collaborate and develop integrated practices to prevent or reduce ACEs and promote resilience.
\end{abstract}

Keywords Adverse childhood experiences $\cdot$ Financial security $\cdot$ Financial wellbeing $\cdot$ Financial stress $\cdot$ ACE

JEL $\mathrm{D} 10 \cdot \mathrm{G} 50 \cdot \mathrm{I} 31$

\section{Introduction}

Research in public health clearly illustrates that adverse childhood experiences (ACEs) have negative, lasting impacts on health and wellbeing (e.g., Asmundson \& Afifi, 2020). These traumatic experiences that occur prior to age 18 lead to toxic levels of stress in adulthood. In this study, we add to the findings about outcomes that result from ACEs by showing that childhood trauma is also linked to adult financial stress. Recognizing this link can lead to improved policy responses to crises as it fosters an increased urgency for efforts to prevent or reduce ACEs and promote resilience. Recognizing this link can also lead to improved practices

Cynthia L. Harter

Cynthia.Harter@eku.edu

John F. R. Harter

John.Harter@eku.edu

1 College of Business, Eastern Kentucky University, Richmond, KY, USA and collaboration by educators, therapists, social workers, and other professionals.

The Consumer Financial Protection Bureau (CFPB) has developed a multi-dimensional financial wellbeing framework that includes an element of financial security. We use data from the Behavioral Risk Factor Surveillance System to create empirical measures of this financial security and investigate influences on respondents' self-assessments of it. While income is a primary influence, we find that, across income levels, having experienced childhood trauma as defined by answers to questions about ACEs is linked to adult financial insecurity about food and housing expenses. The next section of the paper provides a review of relevant background literature to illustrate how this paper expands knowledge in this area and is followed by a discussion of the data, a presentation of estimations and results, and a concluding section. 
Fig. 1 The Four Elements of Financial Wellbeing (CFPB, 2015, p. 19)

\begin{tabular}{|l|l|l|}
\hline & \multicolumn{1}{|c|}{ Present } & \multicolumn{1}{c|}{ Future } \\
\hline Security & $\begin{array}{l}\text { Control over your day-to-day, } \\
\text { month-to-month finances }\end{array}$ & $\begin{array}{l}\text { Future capacity to absorb a financial } \\
\text { shock }\end{array}$ \\
\hline Freedom of Choice & $\begin{array}{l}\text { Financial freedom to make choices } \\
\text { to enjoy life }\end{array}$ & $\begin{array}{l}\text { On track to meet your } \\
\text { financial goals }\end{array}$ \\
\hline
\end{tabular}

\section{Background}

In a report about financial literacy education, the CFPB stated, "The ultimate measure of success for financial literacy efforts should be improvement in individual financial well-being," which is consistent with the vision of the Organisation for Economic Co-operation and Development's (OECD) International Network on Financial Education (CFPB, 2015, p. 4). This multi-dimensional measure is, of course, a broader goal than focusing on a particular financial decision or behavior (as in Diener \& Diener, 2009; Michaelson et al., 2009; Pollard \& Lee, 2003; Stiglitz et al., 2009). In the 2015 report that documents nearly 60 hours of open-ended interviews with adult consumers and financial practitioners, the CFPB concluded that financial wellbeing is driven by financial behaviors, financial knowledge, and personal traits and is defined as "the state of being that is meant to result from high levels of financial literacy and capability" (CFPB, 2015, p. 10).

Drever et al. (2015), reached a similar conclusion as they summarized research findings on financial behavior as determined by basic financial knowledge (as documented in Lusardi \& Mitchell, 2007), financial research and critical thinking skills (as documented by CFPB, 2015, and the OECD Programme for International Student Assessment, 2013), and also life skills such as self-control (as documented by Moffitt et al., 2011). Financial self-efficacy also helps consumers translate abilities into behaviors as shown by Danes et al. (1999). This wide range of skills and attitudes must be combined with financial knowledge to achieve some level of financial wellbeing. While this wellbeing is multifaceted and complicated (Sano et al., 2011), Drever et al., (2015, p. 14) add that "careful consideration of the role of childhood experiences on the development of financial wellbeing could yield valuable insights."

By focusing on financial wellbeing as defined as being able to fully meet current and ongoing financial obligations, feeling secure in one's financial future, and being able to make choices that allow enjoyment of life, the CFPB is defining an interdisciplinary concept that includes aspects such as psychology and health concerns. This study incorporated some of these interdisciplinary characteristics into economic analysis. The CFPB report (2015) described financial wellbeing as a continuum that ranges from severe financial stress to being highly satisfied with one's financial situation, and results showed that one's level of financial wellbeing is not strictly aligned with income level. A poor person, for example, might report a high level of financial wellbeing while someone with a much higher level of income might report a much lower level of financial wellbeing. We provided separate models for different income ranges to investigate influences on financial wellbeing for the different groups.

There were two common themes that appeared consistently in the CFPB survey results - security and freedom of choice, both in the present and in the future. Figure 1, which was included in the report, illustrates how these elements vary for different time frames. For the purposes of this study, we focused our analysis on the top, left element in the diagram. A person who possesses this aspect of financial wellbeing has a relatively high level of financial wellbeing and feels in control of her day-to-day financial life. She is able to manage her finances, cover expenses, and pay bills on time, and does not worry about having enough money to get by. This is the aspect of financial wellbeing that was mentioned most frequently during the CFPB's qualitative interviews (CFPB, 2015). Our study of this element expands the body of research on financial wellbeing which includes projects measuring financial fragility (Hasler et al., 2018), where the focus is on the top, right element of Fig. 1. The CFPB financial wellbeing framework is much broader than the measures used by Hasler et al. and also those used in this study. Data limitations and the level of difficulty involved in developing an empirical model that fully captures all of the elements of the CFPB framework are prohibitive. Thus, we restricted our analysis to the top, left element in Fig. 1. This measure of financial security goes beyond the usual economic concern with income or wealth.

As we investigated determinants of financial wellbeing, we also used public health research findings that suggest the importance of including a measure of childhood trauma in the analysis. There have been a number of studies in behavioral and health sciences that investigate links between knowledge and behavior in terms of biological and mental health (e.g., Kalmakis \& Chandler, 2015; Oral et al., 2016). Financial health has some similarities in that, in all of these situations, people often behave in ways that are contrary to the promotion of their own wellbeing. Research to identify where the link between knowledge and behavior fails in health-related decisions shows a strong relationship between adverse childhood experiences (ACEs) and high-risk behaviors (Campbell et al., 2016; Dube et al., 2003), diseases (Anda et al., 
2008), disabilities (Rose et al., 2014), and workforce issues (Anda et al., 2004).

The original ACE study was conducted by the Centers for Disease Control and Kaiser Permanente and included 17,000 participants who were mostly White, middle- and upper-middle class, college-educated, and all had jobs with good health care (as members of Kaiser Permanente). In the original study (Felitti et al., 1998), individuals had an ACE score of 0 to 10. Each type of trauma counted as one, no matter how many times it occurred so that the measure was a measure of cumulative childhood stresses. Adverse childhood experiences included episodes of physical, sexual, and verbal abuse and physical and emotional neglect, having a family member who is depressed or diagnosed with other mental illness or addicted to alcohol or another substance or in prison, witnessing a mother being abused, and losing a parent to separation, divorce, or other reason.

Primary findings of the study (as summarized by ACEs Too High, 2019) were as follows: ACEs were common with nearly two-thirds (64\%) of adults having at least one; they contributed to adult onset of chronic disease, such as cancer and heart disease, as well as mental illness, violence and being a victim of violence; and, ACEs did not occur alone. If you had one, there was an $87 \%$ chance that you had two or more. On a population level, it does not matter which four ACEs a person has in terms of the harmful consequences. The brain cannot distinguish one type of toxic stress from another, and it all has the same impact. Also, the impacts of ACEs are not strongly related to parental socioeconomic background. Schurer et al. (2019) reported that ACEs impact lifetime economic outcomes through an earnings penalty and increased probability of welfare dependence and poverty regardless of parental socioeconomic background. They also reported that, while ACEs are more common among children from poor families, they impact developmental pathways negatively regardless of parental socioeconomic background.

Adverse childhood experiences are important because these events harm children's developing brains (Carrion et al., 2007). They can change how children respond to stress and damage their immune systems so severely that the effects show up decades later as chronic disease, mental illness, and violent behavior. In addition to physical and mental health manifestations, ACEs might very well have other repercussions due to altered abilities to make sound financial and economic decisions. Research has shown that health problems can affect financial security (Kim \& Lyons, 2008), and we hypothesized that ACEs might also be linked to financial wellbeing in adulthood.

\section{Data and Variables}

Given the findings about the impacts of ACEs on brain development and decision making regarding health, we hypothesized that there is a link between ACEs and financial wellbeing. Specifically, adults who report the occurrence of ACEs are more likely to experience financial stress in adulthood, which is part of the CFPB's financial wellbeing framework. To test the hypothesis, we used data from the Centers for Disease Control and Prevention's Behavioral Risk Factor Surveillance System (BRFSS). BRFSS is an annual, state-based, random-digit-dial telephone (both landline and mobile phone) survey that collects data from non-institutionalized U.S. adults regarding health conditions and risk factors. The survey was established in 1984 with 15 states and now collects data in all 50 states, the District of Columbia, and three U.S. territories. The questionnaire has three parts that include a core component with questions about demographics and current health behaviors, optional modules, and state-added questions. All health departments must ask the core component questions without modification in wording, and the additional modules are optional. The primary objective of the survey is to assess risk for behaviors and health conditions associated with the leading causes of death. More than 400,000 interviews are completed annually which, according to the Centers for Disease Control and Prevention (CDC), makes it the largest continuously conducted health survey system in the world (CDC, 2014).

Optional modules are provided each year, and different states administer different additional modules each year. An Adverse Childhood Experience Module, adapted from the original CDC-Kaiser ACE Study, was added in 2009 and is used to collect information on two categories of ACEs, namely child abuse and household challenges. A Social Context Module was added in 2012 and includes measures of respondents' perceptions of their socioeconomic vulnerabilities - for example, worry about food security or payment for housing. For the purposes of this study, we searched for years in which states chose to administer both the Social Context Module and the ACE Module. In 2012, both North Carolina and Tennessee administered these optional modules, so we restricted our analyses to these states in that year to investigate the relationship between ACEs and adult financial stress.

In 2012, the BRFSS survey results were weighted using raking procedures to adjust the sampling weights based on known population characteristics. The aggregate BRFSS combined landline and cell phone dataset was built from the landline and cell phone data submitted for 2012 and includes data for 50 states, the District of Columbia, Guam, and Puerto Rico (CDC, 2014). Because the data 
were built using complex sampling methods, the sample is not random, and our estimation procedures are adjusted accordingly using sampling weights provided as part of the dataset.

As illustrated previously in the CFPB diagram, financial security is an indicator of financial wellbeing. Due to data limitations, we were unable to include all of the components of the CFPB's financial wellbeing score, but the CFPB framework informs our study where we are using housing security and food security as indicators of wellbeing that encompass psychological and sociological aspects as well as economic considerations in responses. Specifically, we used the answers to the following two questions that were asked on the 2012 BRFSS Social Context Module:

- How often in the past 12 months would you say you were worried or stressed about having enough money to pay your rent/mortgage? Would you say you were worried or stressed

\section{Always \\ Usually \\ Sometimes \\ Rarely \\ Never}

- How often in the past 12 months would you say you were worried or stressed about having enough money to buy nutritious meals? Would you say you were worried or stressed
Always
Usually
Sometimes
Rarely
Never

We examined the relationship between financial insecurity and demographic, socioeconomic, and childhood factors in a model similar to that used by Mustapha et al. (2016), where the authors used ordered probit modeling to investigate determinants of household food insecurity in northern Ghana. We analyzed two models of financial stress. In the first, the dependent variable measured housing security (House Secure), and, in the second, the dependent variable measured food security (Food Secure). The dependent variables were constructed from the questions above where House Secure equalled one if the respondent is always stressed about having enough money to pay for housing, two if usually stressed, and so on, such that five meant the respondent is never stressed (or always secure) about having enough money to pay for housing. The variable Food Secure was constructed in the same manner using the results from the question about stress related to the purchase of nutritious meals. Independent variables included respondent's age, marital status, education level, income, race, gender, number of children under 18 currently living in the home, ACEs total, and a dummy variable to distinguish North Carolina residents from Tennessee residents. Variable definitions are provided in Table 1.

Figure 2 illustrates the prevalence of the different types of ACEs in our dataset (itemized in the footnote for Table 1). As stated previously, it has been shown that all of the ACEs cause childhood trauma regardless of which ones are experienced. ${ }^{1}$ Figure 2 shows that all eleven types asked on the optional ACE module in 2012 were present in our sample. The first six in the figure are questions about the respondent's living situation or household challenges, and the last five ACEs are questions regarding actions about child abuse or things that happened to the respondent. The most common ACE that was reported was having a parent or adult in the home swear at you, insult you, or put you down with $27 \%$ of respondents reporting that this happened to them before age 18 . This is followed by having parents who were separated or divorced with $25 \%$ and living with someone who was a problem drinker or alcoholic with $24 \%$.

Descriptive statistics are provided in Table 2 where we have omitted observations where respondents said they did not know the answer, did not recall the answer, refused to answer, or gave an answer that did not fit any conventional category. Results are presented for North Carolina, for Tennessee, and for the entire 2012 dataset for the sake of comparison. Respondents have more food security than housing security in all of the locations. The two states we studied were not considerably different from the overall survey sample in terms of the dependent variables although there was more financial stress, on average, in respondents from North Carolina and Tennessee than in the overall sample. For all three groups, the average age is mid-50 s with about one-half married, about $60 \%$ having completed at least one year of college or technical school, and about $60 \%$ female. All three groups had an average of

\footnotetext{
${ }^{1}$ Using a cumulative number of ACEs experienced has been criticized, partly because it does not differentiate among the various types (McLaughlin \& Sheridan, 2016). It is clear that these adverse childhood experiences can be traumatic for children, but divorce is an example where research has questioned whether there might be more stress in a family situation before divorce occurs than after. Veevers (1991), for example, examines the literature on responses of married persons to divorce and suggests that the orientation of "divorce as disaster" be replaced with "divorce as development" (Veevers 1991, p. 119). She acknowledges that divorce is traumatic and painful even under that characterization but concludes that divorce can be an opportunity for growth. Perhaps recovery from other living challenges have the potential for growth, too, but they all involve pain and trauma for children who live in the situation.
} 
Table 1 Variable definitions

\begin{tabular}{ll}
\hline Variable & Definition \\
\hline House secure & Categorical variable $=1$ if Always worried or stressed about having enough money to pay rent/mortgage in past 12 months; \\
& $=2$ if Usually; \\
& $=3$ if Sometimes; \\
& $=4$ if Rarely; \\
& $=5$ if Never \\
& Categorical variable $=1$ if Always worried or stressed about having enough money to buy nutritious meals in past 12 months; \\
Food secure & $=2$ if Usually; \\
& $=3$ if Sometimes; \\
& $=5$ if Rarely; \\
& Respondent's age in years \\
Age & Dummy variable $=1$ if respondent is married; 0 otherwise \\
Married & Dummy variable $=1$ if respondent has attended college or technical school for at least one year; 0 otherwise \\
College & Dummy variable $=1$ if respondent's annual household income from all sources is equal to the 2012 U.S. approximate median \\
High income & value of $\$ 50,000$ or higher; 0 otherwise \\
White & Dummy variable $=1$ if respondent is white; 0 otherwise \\
Female & Dummy variable $=1$ if respondent is female; 0 otherwise \\
Kids & Number of kids under 18 who currently live in household \\
ACE total & Sum of values of Individual ACE dummy variables - indicates total number of types of ACEs experienced (maximum value of \\
NC & $11)^{\mathrm{a}}$
\end{tabular}

${ }^{a}$ Questions about ACEs are asking an adult respondent to recall experiences that occurred prior to age 18. On the 2012 BFRSS, ACEs include these 11 types of occurrences: (a) Living with someone who was depressed, mentally ill, or suicidal, (b) Living with someone who was a problem drinker or alcoholic, (c) Living with someone who used illegal street drugs or who abused prescription medications, (d) Living with someone who served time or was sentenced to serve time in a prison, jail, or other correctional facility, (e) Having parents who were separated or divorced, (f) Witnessing parents or adults in your home slap, hit, kick, punch, or beat each other up, (g) Having a parent or adult in the home hit, beat, kick, or physically hurt you in any way (not including spanking), (h) Having a parent or adult in the home swear at you, insult you, or put you down, (i) Having someone at least 5 years older than you or an adult touch you sexually, try to make you touch them sexually, or force you to have sex (three different types of ACE)

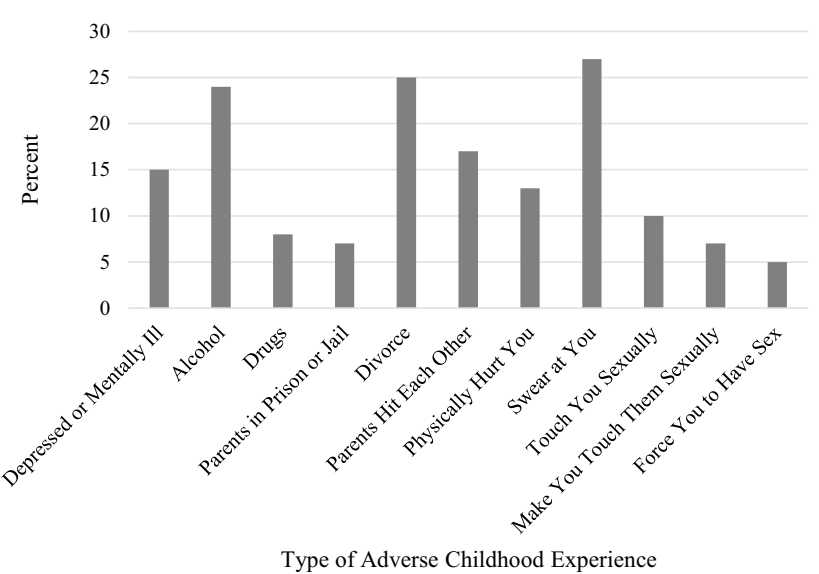

Fig. 2 Percentage of Respondents Reporting ACEs by Type

about 0.50 children under 18 living at home. The overall sample had a higher average percentage of high-income respondents than North Carolina and Tennessee, and both of those states had a higher average percentage of Whites than the overall sample. The average number of ACEs for both North Carolina and Tennessee was higher than for the whole sample. In evaluating pairwise correlation among the independent variables in the model, we observed no noteworthy issues.

For the rest of the analyses, we restricted our attention to the sample containing responses from North Carolina and Tennessee where respondents answered core questions, social context questions, and questions about adverse Childhood Experiences. Tables 3 and 4 illustrate the frequencies for the dependent variables where we see, again, that there is more security about food than about housing among respondents. Two-thirds of respondents have rarely or never within the past 12 months been worried or stressed about having enough money to make rent or mortgage payments, and $75 \%$ have rarely or never within the past 12 months experienced stress about having enough money to buy nutritious meals. In both housing payments and food expenses, if the respondent does report experiencing any financial stress during the past twelve months, the most common response regarding the frequency of stress is "Sometimes." 
Table 2 Descriptive statistics for 2012 BFRSS

\begin{tabular}{|c|c|c|c|c|c|c|c|c|c|}
\hline \multirow[t]{2}{*}{ Variable } & \multicolumn{3}{|c|}{ North Carolina } & \multicolumn{3}{|c|}{ Tennessee } & \multicolumn{3}{|c|}{ All 2012 respondents } \\
\hline & Count & Mean & S. D. & Count & Mean & S. D. & Count & Mean & S. D. \\
\hline House secure & 9,880 & 3.94 & 1.36 & 5,312 & 3.94 & 1.46 & 49,377 & 4.03 & 1.30 \\
\hline Food secure & 8,328 & 4.27 & 1.18 & 4,137 & 4.07 & 1.35 & 54,726 & 4.34 & 1.12 \\
\hline Age & 8,328 & 53.64 & 16.88 & 4,137 & 54.81 & 16.06 & 401,066 & 54.52 & 17.10 \\
\hline Married & 8,328 & 0.52 & 0.50 & 4,137 & 0.50 & 0.50 & 401,066 & 0.53 & 0.50 \\
\hline College & 8,328 & 0.62 & 0.49 & 4,137 & 0.57 & 0.50 & 401,066 & 0.63 & 0.48 \\
\hline High income & 8,328 & 0.53 & 0.50 & 4,137 & 0.48 & 0.50 & 401,066 & 0.58 & 0.49 \\
\hline White & 8,328 & 0.72 & 0.45 & 4,137 & 0.84 & 0.37 & 401,066 & 0.45 & 0.50 \\
\hline Female & 8,328 & 0.59 & 0.49 & 4,137 & 0.63 & 0.48 & 401,066 & 0.58 & 0.49 \\
\hline Kids & 8,328 & 0.52 & 0.99 & 4,137 & 0.47 & 0.94 & 401,066 & 0.55 & 1.04 \\
\hline ACE total & 8,328 & 1.53 & 2.04 & 4,137 & 1.69 & 2.20 & 29,559 & 1.47 & 2.03 \\
\hline $\mathrm{NC}$ & - & - & - & - & - & - & 475,687 & 0.03 & 0.16 \\
\hline $\mathrm{TN}$ & - & - & - & - & - & - & 475,687 & 0.01 & 0.12 \\
\hline
\end{tabular}

Table 3 Frequencies for dependent variable housing secure: Are you worried or stressed about having enough money to pay rent or mortgage?

\begin{tabular}{llrr}
\hline Category & Frequency & Percent & $\begin{array}{l}\text { Cumu- } \\
\text { lative } \\
\text { percent }\end{array}$ \\
\hline 1= Always & 1,326 & 11.75 & 11.75 \\
2= Usually & 473 & 4.19 & 15.94 \\
3= Sometimes & 1,925 & 17.06 & 33.00 \\
4= Rarely & 1,510 & 13.38 & 46.38 \\
5= Never & 6,051 & 53.62 & 100.00 \\
Total & 11,285 & 100.00 & \\
\hline
\end{tabular}

Table 4 Frequencies for dependent variable food secure: Are you worried or stressed about having enough money to purchase nutritious food?

\begin{tabular}{llrr}
\hline Category & Frequency & Percent & $\begin{array}{l}\text { Cumu- } \\
\text { lative } \\
\text { percent }\end{array}$ \\
\hline 1= Always & 922 & 7.40 & 7.40 \\
2= Usually & 430 & 3.45 & 10.85 \\
3= Sometimes & 1,776 & 14.25 & 25.09 \\
4= Rarely & 1,400 & 11.23 & 36.33 \\
5= Never & 7,937 & 63.67 & 100.00 \\
Total & 12,465 & 100.00 & \\
\hline
\end{tabular}

\section{Estimation and Results}

We specified the sample design and used an ordered probit model in Stata (StataCorp, 2017) to examine how changes in the predictors impact the probability of observing a particular level of food security and, in a separate model, the probability of observing a particular level of housing security. As a starting point for discussing the results, we can consider the characteristics of the respondent when all dummy variables in the models take the value zero. Such a respondent is a non-White male who is not married, did not attend college, lives in Tennessee, and has an income below the median of $\$ 50,000$. This "benchmark respondent" is of average age (about 48), has an average number of kids under 18 living at home (about 1), and has experienced an average number of ACEs (just under 2). The marginal effects are presented in Tables 5 and 6 where we see that they are similar for the two models. Note that the marginal effects for the discrete independent variables are the probabilities that result when the dummy variable is equal to one while the other variables are held at their mean values. Being older, having attended some college or technical school, and having high incomes increase the probability of never having been worried or stressed about having enough money to make a mortgage or rent payment or to buy nutritious food in the past twelve months. Being female, having more children under 18 living at home, and having experienced more ACEs all decrease the probability of having experienced housing security and food security during the past 12 months. Interestingly, living in North Carolina as opposed to Tennessee is not a significant determinant for housing security but it is significant and increases the probability of food security. None of the signs on the predictors are surprising.

To investigate which determinants have the largest impacts, we can observe the sizes of the marginal effects across the five levels of insecurity which, for a particular explanatory variable, must sum to zero by definition. The variable with the largest positive impact on never experiencing insecurity is income. Holding all other variables at their mean values, having an income above the median level decreases the probability of experiencing food insecurity by a cumulative total of about 30 percentage points (spread 
Table 5 Ordered probit results: determinants of housing security, marginal values

\begin{tabular}{lllllc}
\hline Variable & $\begin{array}{l}\text { Always insecure } \\
\text { dy/dx }\end{array}$ & $\begin{array}{l}\text { Usually insecure } \\
\text { dy/dx }\end{array}$ & $\begin{array}{l}\text { Sometimes insecure } \\
\text { dy/dx }\end{array}$ & $\begin{array}{l}\text { Rarely insecure } \\
\text { dy/dx }\end{array}$ & $\begin{array}{l}\text { Never insecure } \\
\text { dy/dx }\end{array}$ \\
\hline Age & $-0.002^{* *}$ & $-0.001^{* *}$ & $-0.001^{* *}$ & $-0.000^{* *}$ & $0.004^{* *}$ \\
Married & -0.001 & -0.000 & -0.001 & -0.000 & 0.003 \\
College & $-0.019^{* *}$ & $-0.006^{* *}$ & $-0.016^{* *}$ & $-0.004^{* *}$ & $0.046^{* *}$ \\
High income & $-0.118^{* *}$ & $-0.039^{* *}$ & $-0.100^{* *}$ & $-0.024^{* *}$ & -0.001 \\
White & -0.004 & -0.001 & -0.004 & $0.004^{* *}$ & -0.010 \\
Female & $0.020^{* *}$ & $0.007^{* *}$ & $0.017^{* *}$ & $0.003^{* *}$ & $-0.048^{* *}$ \\
Kids & $0.013^{* *}$ & $0.004^{* *}$ & $0.011^{* *}$ & $0.003^{* *}$ & $-0.031^{* *}$ \\
ACE total & $0.015^{* *}$ & $0.005^{* *}$ & $0.013^{* *}$ & 0.001 & $-0.037^{* *}$ \\
NC & 0.003 & 0.001 & 0.003 & -0.007 & \\
\hline
\end{tabular}

Goodness of Fit: $F(9,11,276)=122.99$, Prob $>F=0.000$, Number of obs $=11,285$, Population Size $=7,443,877$

$* \mathrm{p}<.05 . * * \mathrm{p}<.01$

Table 6 Ordered probit results: determinants of food security, marginal values

\begin{tabular}{llllll}
\hline Variable & $\begin{array}{l}\text { Always insecure } \\
\text { dy/dx }\end{array}$ & $\begin{array}{l}\text { Usually insecure } \\
\text { dy/dx }\end{array}$ & $\begin{array}{l}\text { Sometimes insecure } \\
\text { dy/dx }\end{array}$ & $\begin{array}{l}\text { Rarely insecure } \\
\text { dy/dx }\end{array}$ & $\begin{array}{l}\text { Never insecure } \\
\mathrm{dy} / \mathrm{dx}\end{array}$ \\
\hline Age & $-0.001^{* *}$ & $-0.000^{* *}$ & $-0.001^{* *}$ & $-0.001^{* *}$ & $0.003^{* *}$ \\
Married & -0.001 & -0.001 & -0.002 & -0.001 & 0.006 \\
College & $-0.015^{* *}$ & $-0.007^{* *}$ & $-0.024^{* *}$ & $-0.012^{* *}$ & $0.058^{* *}$ \\
High income & $-0.077^{* *}$ & $-0.037^{* *}$ & $-0.027^{* *}$ & $-0.060^{* *}$ & 0.001 \\
White & 0.001 & 0.000 & 0.002 & $0.004^{* *}$ & -0.004 \\
Female & $0.018^{* *}$ & $0.009^{* *}$ & $0.030^{* *}$ & $0.004^{* *}$ & $-0.070^{* *}$ \\
Kids & $0.005^{* *}$ & $0.002^{* *}$ & $0.008^{* *}$ & $0.008^{* *}$ & $-0.019^{* *}$ \\
ACE total & $0.010^{* *}$ & $0.005^{* *}$ & $0.016^{* *}$ & $-0.007^{*}$ & $-0.038^{* *}$ \\
NC & $-0.009^{*}$ & $-0.004^{*}$ & $-0.014^{*}$ & $0.034^{*}$ \\
\hline
\end{tabular}

Goodness of Fit: $F(9,12,456)=140.08$, Prob $>F=0.000$, Number of obs $=12,465$, Population Size $=8,179,584$

$* \mathrm{p}<.05, * * \mathrm{p}<.01$

over always, usually, sometimes, and rarely insecure), thus increasing the probability of never experiencing food insecurity by about 30 percentage points. The marginal effects are negative for the first four levels of financial insecurity which means that a high-income respondent has a lower probability of experiencing any of those levels of food insecurity or housing insecurity and a higher probability of being never food insecure or housing insecure. Holding all other variables at their mean values, having attended college or technical school for at least one year decreases the probability of experiencing any level of food or housing insecurity by a cumulative total of about 5-6 percentage points and increases the probability of never experiencing food or housing insecurity by about 5-6 percentage points.

The variable with the largest negative impact on the probability of escaping food and housing insecurity is being female. Female respondents are more likely to experience food or housing insecurity always, usually, sometimes, or rarely and less likely to never experience food or housing insecurity as compared to the benchmark respondent. As compared to the benchmark respondent, adding one to the cumulative total of ACEs experienced increases the probability of experiencing food or housing insecurity by a cumulative total of about four percentage points while adding an additional child under the age of 18 currently living in the home increases the probability of experiencing food or housing insecurity by a cumulative total of about 2-3 percentage points. The marginal effects of each of these independent variables is positive for the first four categories of food and housing insecurity and negative for the category of never experiencing food or housing insecurity.

Because income is a principal determinant of financial wellbeing, we investigated the influence of the other independent variables on samples with different income levels to ensure robustness of the results. Studies such as Halfon et al. (2017) have shown that ACEs are distributed across incomes 
Fig. 3 Distribution of ACEs by Household Income Range

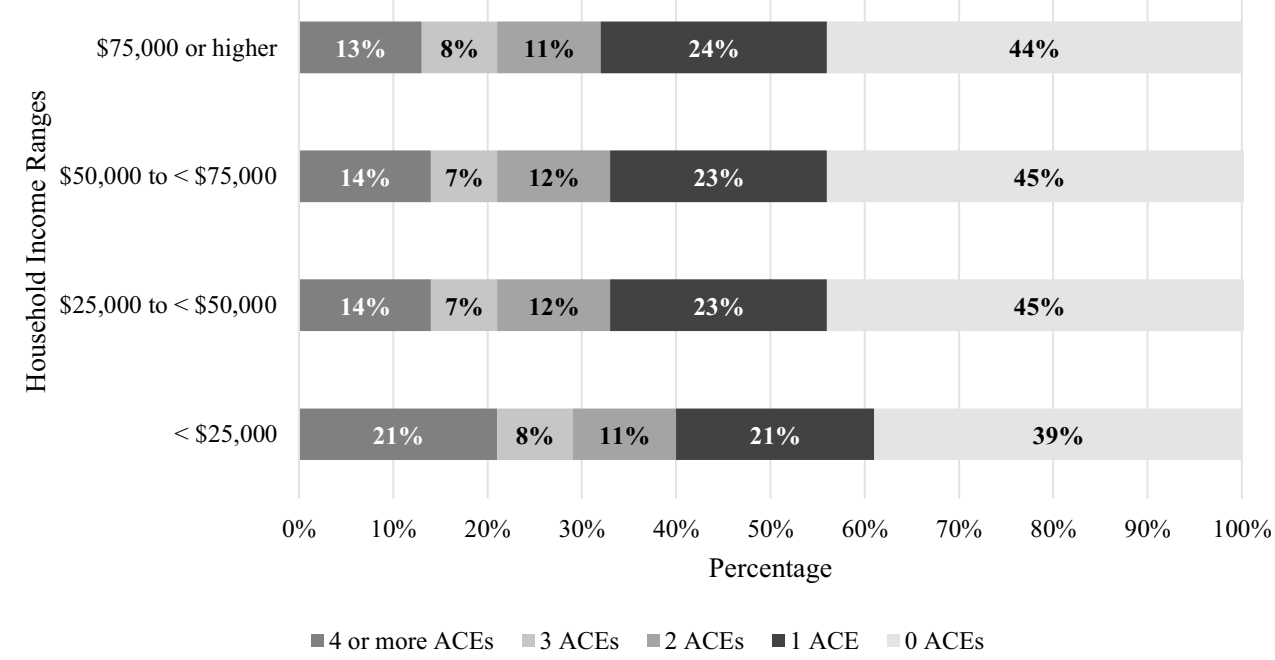

and that having a high income does not protect a household from ACEs, and this is accurate for our dataset as illustrated in Fig. 3. The most notable differences among the income ranges are the higher percent of households experiencing four or more ACEs and the lower percent of households experiencing zero ACEs in the lowest income range as compared to the others.

To investigate the role of income in adult financial wellbeing more explicitly, we separated the data into high income and low income respondents and did not find any differences that changed the primary finding that childhood trauma is linked to adult financial stress, although impacts are more pronounced for low-income households. ${ }^{2}$ We also divided the data into the separate income ranges shown in Fig. 3 and estimated the ordered probit model for each income range. While there are some differences in results for the different groups, the influence of ACEs is still statistically significant for all income groups for both food security and housing security. That is, having experienced more ACEs decreases financial wellbeing, no matter the household income level. Age is also a significant influence for all income groups,

\footnotetext{
${ }^{2}$ Estimating the two separate models where one was comprised of households with income levels below the median and the other was comprised of households with income levels above the median showed only a few notable changes in the results. For the "benchmark" respondent described earlier, increasing the cumulative total of ACEs experienced by one decreased the probability of never experiencing food or housing insecurity by about one percentage point more for low-income households than for high-income households. Also, being married contributed positively to food and housing security for high-income households but was not a significant determinant for low-income households. Living in North Carolina was positive and significant for food security for low-income households but not for high-income households. Overall, the results confirmed the importance of income in food and housing security.
}

where being older leads to more food security and housing security. Differences that are statistically significant include marital status where being married is a negative influence on financial security only for the lowest income group, gender where being female leads to less food security for all income levels and less housing security only for the middle income ranges of $\$ 25,000-\$ 50,000$, having a college education which leads to more food security for the lowest income group and more housing security for the highest income group, and having kids living at home which leads to less financial security for all but the lowest income group.

To further investigate the robustness of these findings, we analyzed varying specifications of the model and analyzed results for different subgroups. When we separated the data by state, we did not find any notable differences in the results for North Carolina and those for Tennessee. In another set of models, we used probit analysis to analyze the impacts of the independent variables on different binary specifications of the housing and food security variables, and results did not change in any notable way. We also divided the data into two groups where one group reported experiencing three or fewer ACEs while the other group reported four or more. Again, we found no differences that changed the primary finding that childhood trauma is linked to adult financial stress.

In investigating subgroups based on geographic differences for respondents, we constructed regional dummy variables for the states, dividing each state into three geographic regions. We also divided the counties into those that are part of Appalachia and those that are not, and we divided them into counties with cities of populations with at least 300,000 persons and those without large cities. None of the regional dummy variables were significant determinants of food or housing security. Also, we estimated a fixed-effects model, specifying the county of residence as the panel variable, and 
the results held up. With no significant differences across groups and specifications, it is clear that ACEs are linked to adult financial wellbeing for all of these subgroups.

\section{Conclusion}

Having experienced more ACEs is correlated with having more financial stress in adulthood as measured by food security and housing security. These results suggest that it is not only physical and mental health that is negatively impacted by ACEs - it is also financial wellbeing. Food insecurity increased in the early part of the twenty-first century (Belistreri, 2016), and events such as the COVID-19 global pandemic increase financial fragility (Clark et al., 2020), especially for groups we have identified as having higher probabilities of financial insecurity. The importance of financial literacy has increased in recent years as today's young adults have watched their parents deal with fallout from the financial crisis of the Great Recession and are also facing large levels of student debt (Houle, 2014). A recent survey shows that Gen Z has notably lower levels of financial literacy than older generations, and now they are facing an economy in slowdown due to the COVID-19 global pandemic (Yakoboski et al., 2021). It is essential to identify factors that contribute to financial wellbeing for individuals and for the global economy as such unexpected shocks occur.

Recognition of this additional link emphasizes the need for policies and practices that prevent or reduce the occurrence of ACEs and promote resilience. As adults suffer trauma and stress, it is important to provide education about healthy coping mechanisms to reduce exposure to ACEs for their children. Building resilience for adults and children can have long-term benefits for mental and physical health outcomes - as well as financial security and wellbeing. The need to account for ACEs affects many fields, such as primary care physicians (Barnes \& Andrews, 2019), social workers (Levenson, 2017), and mental health professionals (Schauss et al., 2019). The resulting policies and practices will need to be multi-faceted and diverse since the causes and manifestations of the effect from ACEs are multi-faceted and diverse, as pointed out in a recent special issue of American Psychologist (Portwood et al., 2021).

Similarly, in our field of economic education, it may be the case that we can change the way financial education is conducted in order to promote lifelong improvements in financial wellbeing. At the precollege level, economic educators could collaborate with those who are experts in the area of social-emotional learning. The interdisciplinary approach could involve the development of a collaborative team of educators who can teach content knowledge and equip students with tools to manage stress simultaneously, leading to better decision making and more successful outcomes in adulthood. This recommendation is timely as education policy makers are recognizing the importance of supporting mental health needs while working to return to face-to-face instruction coming out of the COVID-19 pandemic. An example of training that is taking place is a webinar titled "Lessons from the Field: How Schools and Districts Are Meeting the Social-Emotional and Mental Health Needs of Students and Staff," which was hosted by the National Center on Safe Supportive Learning Environments (NCSSLE) on behalf of the U.S. Department of Education. The webinar featured updates from key federal agencies and included a panel discussion with practitioners sharing lessons learned and best practices designed to support social-emotional and mental health needs at schools (NCSSLE, 2021). The Aspen Institute's National Commission on Social, Emotional, and Academic Development studied "how schools can fully integrate social, emotional, and academic development to support the whole student" and issued a report that included recommendations for researchers, educators, and policymakers (Aspen, 2021, para. 2). Putting social-emotional learning specialists in schools to collaborate with content teachers could improve resilience and weaken the link between ACEs and long-term impacts.

It should be noted that the data regarding ACEs are self-reported with respondents recalling what happened in childhood. Some of the effects are likely attributable to childhood poverty which is not measured separately in the data but which some studies have shown to be strongly associated with the probability of child maltreatment (Cancian et al., 2010; Goldberg et al., 2013). Regardless, childhood distress is linked to lower financial wellbeing in adulthood.

Funding No funds, grants, or other support was received.

Data Availability Center for Disease Control (CDC). (2014). Behavioral Risk Factor Surveillance System 2012 Survey Data and Documentation. https://www.cdc.gov/brfss/annual_data/annual_2012.html.

Code Availability StataCorp. (2017). Stata Statistical Software: Release 15. College Station, TX: StataCorp LLC.

\section{Declarations}

Conflict of interest The authors have no financial or non-financial interests to disclose.

Ethical Approval Institutional Review Board review is not required due to use of preexisting data that is not individually identifiable. 


\section{References}

ACES Too High. (2019). PACEs Science 101. https://www.acest oohigh.com/aces-101/. Accessed 2 Aug 2018

Anda, R. F., Brown, D. W., Dube, S. R., Bremner, D., Felitti, V. J., \& Giles, W. H. (2008). Adverse childhood experiences and chronic obstructive pulmonary disease in adults. American Journal of Preventive Medicine, 34(5), 396-403. https://doi.org/10.1016/j. amepre.2008.02.002

Anda, R. F., Fleisher, V. I., Felitti, V. J., Edwards, V. J., Whitfield, C. L., Dube, S. R., \& Williamson, D. F. (2004). Childhood abuse, household disfunction and indicators of impaired worker performance in adulthood. The Permanente Journal, 8(1), 30-38. https://doi.org/10.7812/tpp/03-089

Asmundson, G. J. G., \& Afifi, T. O. (Eds.). (2020). Adverse childhood experiences: Using evidence to advance research practice policy and prevention. Elsevier Academic Press. https://doi.org/10.1016/ c2017-0-03827-2

Aspen Institute. (2021). National commission on social, emotional, and academic development. https://www.aspeninstitute.org/programs/ national-commission-on-social-emotional-and-academic-devel opment/. Accessed 17 May 2021.

Balistreri, K. S. (2016). A decade of change: Measuring the extent, depth and severity of food insecurity. Journal of Family and Economic Issues, 37(3), 373-382. https://doi.org/10.1007/ s10834-016-9500-9

Barnes, J. S., \& Andrews, M. (2019). Meeting survivors where they are: The vital role of trauma-informed and competent clinicians in primary care. Journal of Aggression, Maltreatment and Trauma, 28(5), 601-612. https://doi.org/10.1080/10926771.2019.1587559

Campbell, J. A., Walker, R. J., \& Egede, L. E. (2016). Associations between adverse childhood experiences, high-risk behaviors, and morbidity in adulthood. American Journal of Preventive Medicine, 50(3), 344-352. https://doi.org/10.1016/j.amepre.2015.07. 022

Cancian, M., Meyer, D. R., \& Reed, D. (2010). Promising antipoverty strategies for children. Poverty and Public Policy, 2(3), 151-169. https://doi.org/10.2202/1944-2858.1085

Carrion, V. G., Weems, C. F., \& Reiss, A. L. (2007). Stress predicts brain changes in children: A pilot longitudinal study on youth stress, posttraumatic stress disorder, and the hippocampus. Pediatrics, 119(3), 509-516. https://doi.org/10.1542/peds.2006-2028

Center for Disease Control and Prevention. (2014). Behavior risk factor surveillance system 2012 survey data and documentation. https:// www.cdc.gov/brfss/annual_data/annual_2012.html. Accessed 31 July 2018.

Clark, R. L., Lusardi, A., \& Mitchell, O. S. (2020). Financial fragility during the COVID-19 pandemic, NBER Working Paper Series, Working Paper 28207, Cambridge, MA: National Bureau of Economic Research. http://www.nber.org/papers/w28207. Accessed 31 Jan 2021

Consumer Financial Protection Bureau. (2015). Financial well-being: The goal of financial education. https://files.consumerfinance. gov/f/201501_cfpb_report_financial-well-being.pdf. Accessed 23 Jan 2019

Danes, S. M., Huddleston-Casas, C., \& Boyce, L. (1999). Financial planning curriculum for teens: Impact evaluation. Journal of Financial Counseling and Planning, 10(1), 26-39.

Diener, E., \& Diener, M. (2009). Cross-cultural correlates of life satisfaction and self-esteem. In E. Diener (Ed.), Culture and well-being (pp. 71-91). Springer. https://doi.org/10.1007/ 978-90-481-2352-0 4

Drever, A. I., Odders-White, E., Lakish, C. W., Else-Quest, N. M., Hoadland, E. M., \& Nelms, E. N. (2015). Foundations of financial well-being: Insights into the role of executive function, financial socialization, and experience-based learning in childhood and youth. Journal of Consumer Affairs, 49(1), 13-38. https://doi. org/10.1111/joca.12068

Dube, S. R., Felitti, V. J., Dong, M., Chapman, D. P., Giles, W. H., \& Anda, R. F. (2003). Childhood abuse, neglect, and household dysfunction and the risk of illicit drug use: The adverse childhood experiences study. Pediatrics, 111(3), 564-572. https:// doi.org/10.1542/peds.111.3.564

Felitti, V. J., Anda, R. F., Nordenberg, D., Williamson, D. F., Spitz, A. M., Edwards, V., Koss, M. P., \& Marks, J. S. (1998). Relationship of childhood abuse and household dysfunction to many of the leading causes of death in adults: The adverse childhood experiences (ACE) study. American Journal of Preventive Medicine, 14(4), 245-258. https://doi.org/10.1016/s0749-3797(98) 00017-8

Goldberg, X., Alemany, S., Fatjó-Vilas, M., González-Ortega, I., González-Pinto, A., Cuesta, M. J., \& Fañanás, L. (2013). Twinbased study of the complex interplay between childhood maltreatment, socioeconomic status and adult memory. European Archives of Psychiatry and Clinical Neuroscience, 263(5), 435-440. https:// doi.org/10.1007/s00406-012-0382-z

Halfon, N., Larson, K., Son, J., Lu, M., \& Bethell, C. (2017). Income inequality and the differential effect of adverse childhood experiences in US children. Academic Pediatrics. https://doi.org/10. 1016/j.acap.2016.11.007

Hasler, A., Lusardi, A., \& Oggero, N. (2018). Financial fragility in the US: Evidence and implications. The George Washington University School of Business.

Houle, J. (2014). A generation indebted: Young adult debt across three cohorts. Social Problems, 61(3), 448-465. https://doi.org/ 10.1525/sp.2014.12110

Kalmakis, K., \& Chandler, G. (2015). Health consequences of adverse childhood experiences: A systematic review. Journal of the American Association of Nurse Practitioners, 27(8), 457-465. https:// doi.org/10.1002/2327-6924.12215

Kim, H., \& Lyons, A. C. (2008). No pain, No strain: Impact of health on the financial security of older Americans. Journal of Consumer Affairs, 42(1), 9-36. https://doi.org/10.1111/j.1745-6606. 2007.00092.x

Levenson, J. (2017). Trauma-informed social work practice. Social Work, 62(2), 105-113. https://doi.org/10.1093/sw/swx001

Lusardi, A., \& Mitchell, O. S. (2007). Financial literacy and retirement planning: New evidence from the Rand American Life Panel. MRRC Working Paper No. 2007-157. https://doi.org/10. 2139/ssrn. 1095869

McLaughlin, K. A., \& Sheridan, M. A. (2016). Beyond cumulative risk: A dimensional approach to childhood diversity. Current Directions in Psychological Science, 25(4), 239-245. https://doi. org/10.1177/0963721416655883

Michaelson, J., Abdallah, S., Steuer, N., Thompson, S., Marks, N., Aked, J., Cordon, C., \& Potts, R. (2009). National accounts of well-being: Bringing real wealth onto the balance sheet. The New Economics Foundation (NEF).

Moffitt, T. E., Arseneault, L., Belsky, D., Dickson, N., Hancox, R. J., Harrington, H. L., Houts, R., Poulton, R., Roberts, B. W., Ross, S., Sears, M. R., Thomson, W. M., \& Caspi, A. (2011). A gradient of childhood self-control predicts health, wealth, and public safety. PNAS, 108(7), 2693-2698. https://doi.org/10.1073/pnas. 1010076108

Mustapha, S., Tanko, M., \& Fatahi Alidu, A. (2016). Determinants of household food insecurity in Northern Ghana: An ordered probit approach. Journal of Economics and Sustainable Development, 7(16), 27-37.

National Center on Safe Supportive Learning Environments. (2021). Lessons from the field: How schools and districts are meeting the social-emotional and mental health needs of students and staff 
[Webinar]. U.S. Department of Education. https://safesupportivel earning.ed.gov/events/webinar/lessons-field-how-schools-distr icts-are-meeting-social-emotional-and-mental-health. Accessed 12 May 2021.

Oral, R., Ramirez, M., Coohey, C., Nakada, S., Walz, A., Kuntz, A., Benoit, J., \& Peek-Asa, C. (2016). Adverse childhood experiences and trauma informed care: The future of health care. Pediatric Research, 79(1), 227-233. https://doi.org/10.1038/pr.2015.197

Organisation for Economic Co-operation and Development. (2013). Programme for international student assessment 2012 Assessment and Analytical Framework. https://www.oecd.org/pisa/pisaproduc ts/PISA\%202012\%20framework\%20e-book_final.pdf. Accessed 18 Dec 2019.

Pollard, E. L., \& Lee, P. D. (2003). Child well-being: A systematic review of the literature. Social Indicators Research, 61(1), 59-78. https://doi.org/10.1023/a:1021284215801

Portwood, S. J., Lawler, M. J., \& Roberts, M. C. (2021). Science, practice, and policy related to adverse childhood experiences: Framing the conversation. American Psychologist, 76(2), 181-187. https:// doi.org/10.1037/amp0000809

Rose, S. M. S. F., Xie, D., \& Stineman, M. (2014). Adverse childhood experiences and disability in U.S. adults. $P M$ and $R$ : the Journal of Injury, Function and Rehabilitation, 6(8), 670-680. https://doi. org/10.1016/j.pmrj.2014.01.013

Sano, Y., Garaski, S., Greder, K. A., Cook, C. C., \& Browder, D. E. (2011). Understanding food insecurity among Latino immigrant families in rural America. Journal of Family and Economic Issues, 32(1), 111-123. https://doi.org/10.1007/s10834-010-9219-y

Schauss, E., Horn, G., Ellmo, F., Reeves, T., Zettler, H., Bartelli, D., Cogdal, P., \& West, S. (2019). Fostering intrinsic resilience: A neuroscience-informed model of conceptualizing and treating adverse childhood experiences. Journal of Mental Health Counseling, 41(3), 242-259. https://doi.org/10.17744/mehc.41.3.04

Schurer, S., Trajkovski, K., \& Hariharan, T. (2019). Understanding the mechanism through which adverse childhood experiences affect lifetime economic outcomes. Labour Economics, 61, 101743. https://doi.org/10.1016/j.labeco.2019.06.007

StataCorp. (2017). Stata statistical software: Release 15. StataCorp LLC.

Stiglitz, J., Sen, A. K., \& Fitoussi, J.-P. (2009). The measurement of economic performance and social progress revisited: Reflections and overview. Commission on the Measurement of Economic Performance and Social Progress, Paris

Veevers, J. (1991). Traumas versus strens. Journal of Divorce and Remarriage, 15(1-2), 99-126. https://doi.org/10.1300/J087v 15n01_07

Yakoboski, P.J., Lusardi, A., \& Hasler, A. (2021). Financial well-being and literacy in the midst of a pandemic: The 2021 TIAA Institute-GFLEC Personal Finance Index. https://www.tiaainstitute. org/sites/default/files/presentations/2021-04/TIAA\%20Institute_ GFLEC_Personal\%20Finance\%20Index_TI_Yakoboski_April\% 202021.pdf. Accessed 17 May 2021.

Publisher's Note Springer Nature remains neutral with regard to jurisdictional claims in published maps and institutional affiliations. 